\title{
O prussianismo e a primazia da política externa no pensamento político de Droysen
}

\author{
Prussianism and the primacy of foreign policies in the political thinking \\ of Droysen
}

\author{
Francesco Guerra \\ fguerra@hotmail.it \\ Pós-doutorando PNPD-Capes \\ Universidade Federal de Goiás \\ Av. Esperança, s/n - Samambaia \\ 74690-900 - Goiânia - GO \\ Brasil
}

\section{Resumo}

Neste artigo é examinada a visão política de Droysen a partir da sua interpretação da política externa desenvolvida por Frederico, o Grande. São abordados, mais especificamente, os modos como Droysen aplicou o conceito de "Estado de paz" (Friedenstaat) nas suas análises de duas situações políticas: uma do passado, a da Prússia de Frederico II, a outra do presente, a da Prússia de Bismarck. Propõe-se também uma interpretação do suposto bismarckismo de Droysen, ou seja, da suposta adesão de Droysen à política externa seguida por Bismarck. Explora-se, nesse sentido, a hipótese um pouco hiperbólica de que não foi tanto Droysen quem se tornou bismarckiano, mas, antes, Bismarck quem se tornou droyseano.

\section{Palavras-chave}

Historiografia alemã; Johann Gustav Droysen; Política.

\begin{abstract}
This article examines Droysen's political vision from his account on the foreign policy of Frederick the Great. The focus here is specifically Droysen's application of the State of Peace's (Friedenstaat) concept on his analysis of two political situations: firstly, the Prussia of Frederick II, and secondly, the Prussia of Bismarck. It also proposes an interpretation of Droysen's supposed Bismarckism, i.e., his supposed adhesion to Bismarck's foreign policy. In this sense, it explores the rather hyperbolic hypothesis that it wasn't so much Droysen that became Bismarckian, but rather Bismarck who became "Droysenian".
\end{abstract}

Keywords

German historiography; Johann Gustav Droysen; Politics.

Recebido em: 11/6/2017

Aprovado em: 12/9/2017 
A articulação decisiva para compreender a posição política de Droysen ao término dos tumultuados anos 40 do século XIX foi representada pela sua participação na Paulskirche de Frankfurt como delegado de Schleswig-Holstein. Foi aquela ocasião que permitiu ao jovem professor pomerano entender o quanto, para o bem ou para o mal, a Prússia haveria de ter uma importância decisiva no futuro do Estado alemão. A recusa por parte de Frederico Guilherme IV da proposta constitucional elaborada no parlamento de Frankfurt evidenciou, por um lado, que pela via parlamentar não seria possível dar uma resposta à Deutsche Frage, senão com o aval decisivo do rei da Prússia. Suscitava, por outro lado, algo como um diagnóstico ainda muito mais grave: o de que a unificação da Alemanha não era uma questão precipuamente nacional, como poderia parecer, mas atingia as concretas relações de força existentes entre as Grossmächte europeias (Cf. CERVELLI 1988, p. 160; HOCK 1957, p. 1, 2, 126, 127).

No seu discurso, Droysen fazia recair a responsabilidade do fracasso de Frankfurt particularmente sobre Frederico Guilherme IV e a sua camarilha, cujo trato antiliberal e ultraconservador sempre lhe parecera anacrônico e prejudicial para o destino da questão nacional. A ausência de aprovação do texto constitucional elaborado pela Paulskirche reforçou em Droysen a sua contrariedade em relação à monarquia encarnada em Frederico Guilherme IV, mas, curiosamente, o mesmo fato o convenceu de que um eventual Reich da nação alemã não poderia surgir senão sob a égide da Prússia (DROYSEN 1929, I, p. 547; 1881, V, III, p. 9). ${ }^{1}$ Esse prussianismo de Droysen foi certamente 136 incentivado pela necessidade de uma pragmatische Politik, que, em diversos ambientes da produção historiográfica e epistolar droyseniana dos últimos anos, volta com certa recorrência. Prussianismo e pragmatische Politik no ideal político droyseniano convergem para uma visão de território alemão - nunca explícita - que o equipara a uma cidadela assediada externamente pelas várias Grossmächte europeias. Essa tese é expressa muitas vezes pelo professor pomerânio: na primeira edição das Vorlesungen über die Freiheitskriege (1846), nas Politische Schriften, cujos ensaios abarcam um arco de tempo que vai de 1844 (Deutsche Briefe) a 1857 (Zur Situation), e nos quatorze volumes que compõem a Geschichte der preussischen Politik (1855-86). ${ }^{2}$

Essa concepção, nos dois volumes publicados em Kiel em 1846, será, sobretudo, referendada em relação à formação da Santa Aliança e à derrota política que ela representou para os territórios alemães e, em particular, para a Prússia. Não foi por acaso que Frederico Guilherme IV aceitou o primeiro volume, enquanto rejeitava o segundo, exatamente pelos ataques ao sistema de Estados europeu, à restauração na qual, após a derrota de Napoleão, o Estado prussiano tinha se empenhado em tomar parte (DROYSEN 1846, p. 714725). Com a Santa Aliança, a Prússia acabou por fazer o jogo das Grossmächte, de todos aqueles Estados europeus - Droysen pensava in primis na Áustria e

\footnotetext{
${ }_{1}^{1}$ Todas as traduções para a língua portuguesa foram feitas pelo autor.

${ }^{2}$ A mudança presente no prussianismo de Droysen depois do fracasso da Paulskirche de Frankfurt é uma mudança de intensidade e não de sustança; ou seja, os elementos do seu prussianismo nunca mudaram em um arco temporal de mais de quarenta anos, só mudando a intensidade da sua opção prussiana.
} 
na França - que nunca teriam tolerado a formação de um Estado alemão no centro da Europa. Frente a uma realidade desse tipo, o liberalismo monárquico e conservador de Droysen parecia não encontrar outra solução além de procurar na história prussiana, na mesma casa dos Hohenzollern, a resposta política às questões, aparentemente insolúveis, colocadas no presente (DROYSEN 1846, p. 3-17). No século XVII, durante a guerra dos Trinta Anos, o Eleitorado da PrússiaBrandemburgo fora governado por um soberano fraco como Jorge Guilherme. Em um momento em que o Estado no qual se concentravam as esperanças do mundo evangélico deveria ter assumido a própria missão histórica, colocando-se acima das falsas alternativas disponibilizadas pelas grandes potências europeias, Jorge Guilherme perseguiu de forma constante uma política defensiva em relação às outras potências, tentando não ser arrastado para o conflito. Durante todo o período em que Jorge Guilherme governou o Estado, as partes que lutavam submeteram o País a constantes saques, enquanto as suas escolhas políticas foram sempre muito influenciadas pelo poder do ministro Schwarzenberg (Cf. DROYSEN 1933, p. 339-340).

O sucessor de Jorge Guilherme, Frederico Guilherme, soube colocar-se acima das oposições de seu tempo, promovendo o interesse alemão - finalmente distinto daquele hasbúrgico - e superando as divergências religiosas entre a fé calvinista e luterana na igualdade e unidade evangélica, enfim, encontrando na ideia monárquica uma solução política válida em relação a toda e qualquer hipótese de classe ou dinastia. Frederico Guilherme foi um verdadeiro inovador no âmbito estatal, e a sua ação política se constituiria como o precedente mais relevante para o que será realizado por Frederico II. Ele subiu ao trono com apenas vinte anos, no momento de máxima fraqueza e humilhação do Eleitorado, merecendo o nome de "grande eleitor" por ter passado a segunda metade do século pós-Guerra dos Trinta Anos colocando em ordem o próprio Estado devastado por essa guerra. O período de quarenta e oito anos em que Frederico Guilherme esteve no trono foi caracterizado pelo renascimento do Eleitorado da Prússia-Brandemburgo (Cf. FLENLEY 1965, p. 49).

O destaque da profunda fraqueza que no curso da história abalou a existência de cada estado presente no solo alemão constitui o centro das reflexões do texto que remonta a 1849, La Prussia e il sistema delle grandi potenze. Frederico II, as maquinações conduzidas pelas potências europeias, em particular pela Áustria e pela França, a entrada da Rússia, por desejo de Maria Teresa d'Áustria, no interior do círculo da política ocidental, são elementos de uma análise voltada para restaurar uma imagem de Frederico e do seu Estado como totalmente independente em relação às grandes potências e, ao mesmo tempo, como verdadeiro "fiel da balança do equilíbrio político europeu" (DROYSEN 1933, p. 214-215; cf. TAYLOR 1963, p. 39). O que mais marca essa interpretação não é, no entanto, a sua referência à Prússia como o verdadeiro árbitro das questões internas e externas ao solo alemão, mas que tais pensamentos seriam mais adequados à grande derrota de Jena em 1806 e não à situação vivida pela Prússia em 1849. Ao mesmo tempo, os tons e conteúdos utilizados por Droysen para garantir o próprio ponto de vista prussiano evidenciam uma identidade 
que deveria concretizar-se na fundação de um Estado alemão independente. Tratar-se-ia da libertação de uma condição de minoria política em relação às outras grandes potências continentais pela substituição de Viena por Berlim e, por conseguinte, do Estado austríaco - incapaz de guiar os destinos do povo alemão - pelo prussiano. Frederico lutava pela Prússia contra as outras potências europeias, mas a sua tentativa perseguia um projeto mais ambicioso, que era a libertação da Alemanha. A unificação da Alemanha sob a égide da Prússia teria, pois, significado a instauração de uma política de equilíbrio em todo o continente. Portanto, pelo menos nas intenções, a "potência da política" ter-seia imposto à "política da potência".

\section{A política externa de Frederico, o Grande, nas páginas da Geschichte der preussischen Politik}

A figura de Frederico, o Grande, é apresentada por Droysen em detalhes, especialmente a partir do primeiro volume da quinta parte da Geschichte der preußischen Politik. Para ele, a entronização de Frederico II marca o início de uma nova era, porque este teria sabido entender, antes de seus contemporâneos, a direção da corrente da história, encarnando pensamentos que até então careciam de um intérprete (Cf. HEGEL 2003, p. 358). A importância de Frederico da Prússia é tal que ele se tornaria um divisor de águas, não só para seu país, mas também para a deutsche Frage de modo geral. Em plena concordância com aquilo afirmado sobre Alexandre, o Grande, na Geschichte Alexanders des

138 Großen, em 1833, Droysen confere às ações do rei um caráter universal que transcende não só a Prússia e a Alemanha, como também as condições gerais de poder e o sistema de Estados. O caráter universal da ação política desenvolvida por Frederico II se manifestou na cena política internacional, propagando-se em camadas cada vez mais profundas e em distâncias cada vez maiores, abrindo espaço para o novo por meio de libertações, revoltas e choques violentos de modo a liquidar «a confusão de séculos, para construir, a partir de novos pensamentos, de novas maneiras, o novo mundo. Ao período de Frederico, segue aquele de Washington e o da Revolução Francesa" (DROYSEN 1874, p. 5). ${ }^{3}$ Do ponto de vista político, pode-se dizer que Droysen vê na Prússia de Frederico a aurora de uma nova era, cujas vibrações se estenderiam no tempo e espaço para inspirar as ações de George Washington e os acontecimentos da Revolução Francesa. Mas o que une essas personagens e eventos senão o fato de que por meio deles o novum pôde se estabelecer na história?

Aos olhos de Droysen, Frederico, Washington e a Revolução Francesa estão unidos pelo fato de serem opostos àquele sistema injusto, arrogante e desprovido de qualquer legitimidade no plano político e histórico que regeu as relações internacionais e que era baseado no poder exercido pelas grandes potências (Großmächte). Na base desse poder, nesse sentido anacrônico, haveria só a defesa dos interesses dinásticos, a qual, desde o Congresso de Viena, havia

\footnotetext{
${ }^{3}$ Com o intuito de rebater possíveis críticas que poderiam ser feitas contra uma exposição histórica deste tipo, Droysen afirma: "Uma coisa é a série de efeitos que este príncipe lançou, outra aquilo que ele quis e fez e como ele o fez. Apenas isso pertence à história prussiana" (DROYSEN 1874, p. 5).
} 
produzido uma intrincada rede de poderes colocada para defender princípios ultraconservadores no continente europeu. O território alemão, frente a esse quadro, parecia ser uma espécie de vítima predestinada, apesar do aval, de fato, dado por Frederico Guilherme IV para tais políticas das grandes potências. ${ }^{4}$ Essas reflexões de Droysen devem ser lidas juntamente com as análises realizadas na primeira elaboração da Historik, a saber, em termos de equilíbrio de forças entre os Estados, os quais derivavam da ausência substancial de um direito internacional legitimado e respeitado (Cf. DROYSEN 1994, p. 488-498).

As maiores dificuldades no âmbito das relações internacionais surgiam pela clara ausência de vontade por parte dos sujeitos jurídicos envolvidos - os Estados - em reconhecer um poder público superior a eles, poder esse que fosse, ao mesmo tempo, formado por eles e independente deles. Essa situação evidenciava que nas relações entre os Estados, o poder, entendido como poder do mais forte, constitui "a base das relações do direito". Embora Droysen pensasse que pelo direito do mais forte tivesse sempre de passar a afirmação da força do direito, ele não escondia que tal ponto de chegada pudesse ter um longo caminho à sua frente (DROYSEN 1994, p. 488-489).

As considerações apresentadas acima ajudam a compreender as diferentes posições de Droysen sobre a articulação do poder no interior do Estado e as situações que em decorrência disso poderiam surgir nas relações interestatais. Por outro lado, a ausência de um direito internacional capaz de regular os equilíbrios de força entre os Estados pode ligar-se à exaltação do Estado prussiano, recorrente após o fracasso da Nationalversammlung de Frankfurt, e também parece dar conta de um certo "realismo político" que às vezes emerge das páginas do professor pomerano. Portanto, a declaração da ausência de uma legislação eficaz no âmbito internacional parece ter como corolário o reconhecimento da potência como único árbitro dos destinos políticos europeus, daí o constante perigo para cada um dos Estados alemães de tornar-se vítima das políticas expansionistas de outros países, especialmente da França e da Áustria. Droysen, desde o tempo da elaboração, em Kiel, de seu trabalho dedicado às Freiheitskriege, estava convencido de que a potência, entendida como a capacidade de defesa de um Estado, ou seja, como aquela opção específica que, sozinha, poderia garantir-Ihe uma liberdade e uma soberania duradoura é o que, em última instância, rege as relações internacionais (Cf. DROYSEN 1994, p. 488-489).

Na interpretação de Droysen, Frederico, o Grande, teria tentado quebrar o sistema de defesa dos interesses dinásticos e trazer a Prússia para o círculo das grandes potências. Com a Liga dos Príncipes, teria apresentado um primeiro projeto de unificação, mas, pelo fato de as suas ações terem sido exitosas, teria tido de demonstrar sua potência perante os inimigos, exaltando a Prússia. ${ }^{5}$

\footnotetext{
${ }^{4}$ As dificuldades para a Prússia nasciam do fato de ser, ao mesmo tempo, parte integrante do sistema das grandes potências e ser dentre elas a menor e, portanto, a mais fraca e mais exposta aos desejos de conquista dos outros Estados, in primis a França e a Áustria. Por isso e pela lembrança das terríveis experiências sofridas pelo povo alemão durante a Guerra dos Trinta Anos, surgiam as preocupações de Droysen nas décadas que precederam a formação do Reich bismarckiano.

${ }^{5}$ Sempre a partir da situação europeia, que foi criada após a Paz de Westphalia, Droysen enfatiza as graves lacunas na jurisdição interestatal: "[...] O direito internacional, que teria de estabelecer a ordem e regular de maneira duradoura a nova comunidade do mundo estatal cristão, por um longo tempo foi resolvido só
} 
O rei, ajudado pela sorte, elemento que não poderia faltar às personalidades históricas droysenianas, teria sabido captar os pensamentos disponibilizados pela sua época. ${ }^{6}$

Nas condições dos Estados restantes, nas falsas relações e nos conflitos das potências frente à crise do sistema estatal que se aproximava, Frederico teria enxergado a oportunidade de apresentar e enaltecer o valor da Prússia, haja vista que esta tinha sofrido de forma mais grave a aversão e a arrogância das grandes potências, o que tinha lhe oferecido a oportunidade para dar os primeiros passos diplomáticos. Mesmo no caso de Frederico, o Grande, Droysen adota o modelo interpretativo já utilizado nesse mesmo trabalho para descrever o sujeito e a obra política realizada pelo "Grande Eleitor" Frederico Guilherme (1620-1688), enquanto no fundo figurava a Guerra dos Trinta Anos com os efeitos de longa duração aos que tinha dado início. ${ }^{7}$ Segundo Droysen, Frederico, o Grande, teria aproveitado a situação de crise nas relações entre os Großmächte e mais ainda o período conturbado que a ideia do Estado, no seu conjunto, estava atravessando na Europa para criar espaço para as aspirações políticas e militares da Prússia. Tais aspirações eram motivadas pelo ressentimento que a Prússia e vários Estados alemães sentiam em relação a essas grandes potências, que tinham escolhido o território alemão como teatro de suas campanhas militares com consequências desastrosas para as populações e uma flagrante violação da sua soberania. Para pôr fim aos abusos dos outros Estados europeus, o historiador pomerano acreditava que não havia outra solução senão aquela já apresentada pelo Grande Eleitor e por Frederico II: transformar a Prússia numa grande potência, eficiente administrativamente e poderosa militarmente. Assim como Alexandre havia subtraído a Grécia ao domínio da Pérsia, unificando-a sob o poder macedônio, Frederico teria começado a "prussianizaçao" do território alemão para subtraí-lo ao domínio das Großmächte. ${ }^{8}$

nos tratados entre Estados e ainda não tinha obtido nos interesses e convicções comuns dos povos uma vida própria e um princípio que fosse capaz de modelar algo. Por isso, permaneceu um esquema vazio, incapaz de comprometer os fortes e proteger os fracos; [...] a casuística de direito civil se impôs também nas questões relacionadas ao direito público e à política" (DROYSEN 1874, p. 6).

${ }^{6}$ Levando em conta o que até agora foi observado, pode-se afirmar que, para Droysen, a história somente pode progredir por via da ação daqueles que poderíamos definir pelo termo Geschichtsbeweger (Frederico, o Grande, Washington). Na Historik, o próprio Droysen usa a expressão Werkmeister der Geschichte (Cf. DROYSEN 1977, p. 388).

${ }^{7} \mathrm{Na}$ terceira parte da Geschichte der preußischen Politik encontra-se a exposição mais completa da política de Frederico Guilherme. Droysen ali traça uma linha entre o Estado territorial de Brandemburgo, a Prússia e aquilo que a partir daí se manteria em um futuro Estado alemão. Frederico Guilherme é nesta leitura o ponto central, porque, com ele, "a história territorial da casa de Brandemburgo termina e começa a história do Estado prussiano" (DROYSEN 1870a). "Uma passagem ainda mais relevante porque se originou durante a Guerra dos Trinta Anos, depois que o Eleitorado tinha sido governado por um soberano fraco como Jorge Guilherme, para realizar-se inteiramente nos anos difíceis que se seguiram àquela guerra. Frederico Guilherme foi o verdadeiro criador da Prússia, um Estado que nasceu no meio dos horrores da guerra e que tinha visto "a ruína de todas as leis, de toda civilização e bem-estar, o horror de um fim geral" (Ibidem). Sobre este discurso, ver FLENLEY 1965, p. 51-62. Finalmente, sobre a figura de Frederico Guilherme, ver Droysen (1870, p. VII; 1871a, p. 371-373).

8 "A Revolução de Março finalmente pareceu entregar nas mãos da nação o seu destino. "A unidade alemã" era a fórmula mágica que prometia curar-nos de todo o mal. Este não é o lugar para discutir a história dolorosa da Assembleia Nacional de Frankfurt. Foi mostrado que a ideia de unidade nacional, não digo que seja falsa ou ilusória, mas ainda não é mais tão poderosa quanto o hábito da fragmentação e do encanto de suas pequenas vantagens, de suas nefastas rivalidades, de sua, poderia dizer-se, tendência suicida diante do mal feito aos outros. Ela produziu efeitos de que ela própria vai ser o resultado" (DROYSEN 1933, p. 222). 
Droysen resume a perspectiva de Frederico II sobre os acontecimentos políticos de sua época num parágrafo intitulado Friedrichs II. politische Umschau ( $A$ análise política de Frederico $I I$ ). Nesta fase, Frederico II teria percebido que o quadro da política europeia estava se delineando cada vez mais como um conflito entre a França e a Inglaterra. Essa polarização, na perspectiva das novas relações de poder entre os Estados europeus, tinha de ser evitada para que a Prússia não sucumbisse "à dominação mercantil da Inglaterra ou à política da França" (DROYSEN 1933, p. 222). A Paz de Breslau (1742) parecia ser a sanção política que o monarca da Prússia perseguia desde a sua coroação e teria contribuído para fazer com que os gabinetes da Europa viessem a ver a Prússia não mais como a menor das grandes potências, mas sim na mesma posição delas. ${ }^{9}$ (Cf. DROYSEN 1876, p. 113-114). Mediante a Paz, a permanência da estrutura antiga dos Estados, solicitada pela Inglaterra à corte de Viena, foi mantida, e o resultado mais importante foi "um novo Estado militar, protestante e alemão [...] acrescentado à série das potências proeminentes" (DROYSEN 1876, p. 113-114).

Droysen aponta que, com anedotas e boatos, procurou-se desacreditar a imagem política de Frederico da Prússia, mas isso não produziu os efeitos desejados. Procurou-se mostrar, ainda, com novas provas, que ele era o príncipe mais ambicioso, perigoso e traiçoeiro que a história havia conhecido, afirmandose que todos os seus esforços no âmbito internacional seriam destinados apenas a conquistar novos territórios para o seu Estado (DROYSEN 1876, p. 113-114). No entanto, aponta Droysen,

Nas declarações mais íntimas do rei não há qualquer vestígio de tais pensamentos. Na verdade, ele escreveu em 1746, em sua história desses anos: "Toda a minha atenção tinha sido dirigida apenas para manter o imperador honestamente em seu lugar e a estabelecer a paz mundial; eu pedi moderação a todas as potências; tentei acalmar umas e refrear outras. Com isso esperava como consequência que o óleo não fosse mais jogado no fogo; sem comida para fazer, o fogo se apagaria" (DROYSEN 1876, p. 113-114).

A Prússia de Frederico, particularmente de 1740 a 1756, pensa Droysen, voltava-se mais para os Estados e as outras potências, porque teria entendido e tentado resolver o problema que teria perturbado esse século e os subsequentes (DROYSEN 1881, p. 6). Por meio de uma linguagem evocativa, mas não totalmente esclarecedora, Droysen refere-se, de certo modo, à substância teórica da sua Geschichte der preussischen Politik: a questão

\footnotetext{
${ }^{9} \mathrm{Na}$ realidade, tratou-se de um armistício; todavia, a paz foi consolidada pouco depois. Droysen ainda observa: "Como é difícil para os contemporâneos reconhecer e aceitar na confusão dos eventos que os fatos, certamente mais que apenas fatos, sejam efeitos e tornem-se causa, que sejam concluídos e realizados em seus princípios e que, a partir de agora, devem ser levados em conta" (DROYSEN 1876, p. 113). A primeira Guerra da Silésia (1740-1742) foi parte da Guerra de Sucessão austríaca, travada entre 1740 e 1748 , tendo de um lado a Prússia, a Baviera, a França, a Saxônia, a Colónia, a Espanha, a Suécia e o Reino das Duas Sicílias, e, do outro, os exércitos dos Habsburgos e seus aliados (Grã-Bretanha, Reino da Sardenha, Holanda e Rússia). O objetivo declarado de Frederico era a Silésia, que era parte dos domínios austríacos. Após duas campanhas, travadas respectivamente em 1741 e em 1742, em 11 de junho de 1742 foi assinado, em Wroclaw, o armistício, no qual a Baixa Silésia, a Alta Silésia até o rio Opava e o condado da Boêmia de Glatz foram atribuídos à Prússia. Em 28 de julho, finalmente, a Paz de Berlim confirmou os acordos alcançados em Wroclaw.
} 
nacional. A Prússia de Frederico, o Grande, elaborou uma questão semelhante, mesmo sem unificar o fragmentado território alemão num Estado nacional sob a égide da monarquia prussiana:

Esse Estado não tinha surgido da vontade e do empenho de uma nação que buscava novas formas para a sua existência política, nem com base numa única confissão religiosa de um território naturalmente similar e compacto ou de interesses iguais ou que se integravam. Ele não era a dominação de um país ou de um povo sobre outro subjugado, nem a livre união pessoal de diferentes coroas e países. Haviam nele, menos ainda, combinações de política geral ou previdentes decisões de proeminentes potências. O seu princípio se dá quando, mesmo no meio dos choques violentos da Guerra dos Trinta Anos, a forte vontade e a mão segura de um príncipe reuniram monarquicamente os direitos dinásticos, de que ele era o herdeiro, e deram forma à unidade estatal (DROYSEN 1881, p. 31-32). ${ }^{10}$

Não se trata de encontrar uma causa principal, como o "fundamento de uma única confissão religiosa", "um território naturalmente similar e compacto" ou a presença de "interesses iguais ou que se integram", nem mesmo uma necessidade percebida para criar o Estado a partir "da vontade e do compromisso de uma nação" à procura de novas formas de existência política e, muito menos, do resultado de escolhas feitas pelas grandes potências à custa, e não para o benefício, do território prussiano.

Novamente, o progresso é confiado por Droysen a um desses indivíduos históricos, os quais, na sua reflexão, parecem sempre ultrapassar o espaçotempo que ocupam. ${ }^{11}$ Afinal de contas, era uma posição totalmente coerente com as mesmas opiniões políticas expressas pelo professor pomerano. A figura do indivíduo que, antes daqueles que o rodeiam, reconhece a direção da corrente da história, compreende as necessidades da sua época e pode suprilas, reconduz à droyseniana desconfiança em relação à massa ativa e agente na história, bem como em relação a uma ordem democrática do Estado que, no plano formal, sancionaria o poder expresso por tal massa.

\section{O Friedenstaat}

As reflexões estruturadas pelo historiador pomerano sobre o conceito de Friedenstaat constituíam o último apêndice de uma ideia que surgira a partir dos estudos sobre a Altertumswissenschaft e que, por conseguinte, permeava o seu pensamento histórico e político. A Prússia, entendida como o Estado que teria preservado a Europa de novos conflitos, encontra-se no último volume da Geschichte der preussischen Politik e também em um artigo de 1879 dedicado às relações entre a Inglaterra e a Prússia nos anos de 1740-1746. Anteriormente, Droysen se detivera sobre esse tema nos três ensaios do período de Kiel: Die politische Stellung Preussens (1845), Die attische Communalverfassung (1847)

\footnotetext{
${ }^{10}$ A referência de Droysen é ao grande eleitor Frederico Guilherme, cujo projeto político de fortalecimento da Prússia e unidade da Alemanha seria retomado e parcialmente realizado por Frederico II.

${ }_{11}$ Embora esta parte de seu trabalho seja dedicada à figura de Frederico, o Grande, Droysen aqui faz uma nova referência ao grande eleitor Frederico Guilherme, fundador do Estado prussiano. Sobre a distinção entre Werkmeister e Arbeiter na obra de Droysen sobre o Marechal Yorck von Wartenburg, cf. Assis (2014, p. 157).
} 
e Preußen und das System der Großmächte (1849). (Cf. DROYSEN 1874, p. 492 ; 1881 , p. 46 ; 1886 , p. $427-428 ; 1879$, p. $502-534 ; 1893$, p. 383-385; 1933, p. 62-63 e 212-229).

O que parece unir esses escritos, mesmo sob uma atmosfera política diferente, é a profunda convicção de Droysen de que a paz na Europa precisaria de uma política prussiana conduzida com mão firme, sobretudo para chegar à unidade da Alemanha. Em contrapartida, a Alemanha, para unificar-se, por sua vez, precisaria de um período de paz duradoura no âmbito da política europeia, o que não era nada simples. Tratava-se de um processo que poderia ser combinado a eventos específicos por ele investigados em seus trabalhos sobre Alexandre, o Grande, e o helenismo, dos quais se tem um testemunho consistente no ensaio de 1847. Enfim, a substância do raciocínio não é tanto histórica - tendo em conta a adequação ou não à realidade dos fatos de um Frederico II animado por sinceras intenções de paz - quanto filosófica.

Antes da formação do Reich, em 1871, Droysen tinha encontrado semelhanças específicas entre o período de Alexandre, o Grande, o Eleitorado de Prússia-Brandemburgo no tempo do Grande Eleitor e, mais tarde, de Frederico II e aquilo que, naquele momento, impedia os vários territórios alemães de unir-se num único Estado. Igualmente, tais afinidades parecem referir-se a um quadro da história universal que em Droysen permanece essencialmente idêntico, mesmo durante um longo período de tempo, e que viria a constituir sua base filosófica de pensamento, o que está na base dos argumentos propriamente históricos desenvolvidos nas obras. No entanto, é sempre difícil seguir Droysen em digressões sobre o Estado prussiano. Por outro lado, a partir desse conjunto de circunstâncias externas, forma-se a imagem de uma Prússia e, em perspectiva, da Alemanha, entendida como aquele Estado que teria assegurado a preservação da paz na Europa. Seguindo o caminho não revolucionário, através de uma ação que teria começado diretamente por meio do rei, a Prússia seria dotada de uma nova estrutura estatal. Este Estado teria conciliado a centralização e a energia do Estado francês revolucionário com a particularidade da sociedade civil, da liberdade burguesa da Inglaterra feudal e conservadora. A oposição entre burguês e cidadão tinha de ser ultrapassada por meio do Estado burguês geral; mantinhase a divisão das formações nascidas na sociedade civil (Stände), mas a servidão seria eliminada, bem como a opressão social, e todos os habitantes se tornariam cidadãos livres (BRAVO 1968, p. 278-279).

Esse liberalismo monárquico, em termos institucionais, configurava-se como um reconhecimento de uma representação das diferentes formações nascidas na sociedade civil (Stände) no interior do Parlamento, cuja ação tinha de harmonizarse com aquela do monarca. No entanto, esse último mantinha, segundo Droysen, prerrogativas mais importantes do que um Parlamento, no qual os diferentes representantes políticos poderiam ver-se em conflito entre si, mesmo no interior do mesmo grupo político. O rei, portanto, poderia garantir a estabilidade política necessária no interior do Estado, o que, pelo contrário, um parlamentarismo ainda incipiente e imaturo não teria sido capaz de fazer. Entretanto, o Estado alemão do futuro, entendido como Friedenstaat, não convence. 
O argumento de uma Prússia e uma Alemanha que teriam por missão equilibrar a situação política europeia teve de formar-se em Droysen a partir dos terríveis acontecimentos que o povo alemão havia testemunhado na Guerra dos Trinta Anos. Ele atribuía ao enraizado particularismo (Kleinstaaterei) presente nos diferentes territórios o efeito de ter impedido a união do povo alemão num Estado capaz de defender-se e, portanto, de ter ajudado a causar a própria catástrofe. Embora admitindo tal tipo de leitura, o fato é que Droysen não fornece um argumento satisfatório a esse respeito; pelo contrário, as referências à política externa perseguida por Bismarck, bem como uma grande parte da correspondência com Heinrich von Treitschke, parecem apontar numa direção absolutamente contrária (Cf. GUERRA 2008, p. 567-633). ${ }^{12}$

No momento em que, no centro da sua reflexão, é colocada a questão da necessidade de se unificar a Alemanha, conceitos específicos começaram a assumir uma importância equivalente que anteriormente se encontrava ausente. Aqui surge o problema da Machtpolitik, bem como aquele referente ao papel das grandes personalidades agentes na história, que, como apresentado anteriormente, agora, nas páginas de Geschichte der preussischen Politik, parece ser colocado sob uma nova luz (Cf. GILBERT 1931, p. VII-VIII; HARDTWIG 1980, p. 277-280). Tal circunstância, sem dúvida, afeta o seu prussianismo originário. No entanto, tais deslizamentos se intensificariam após o seu retorno a Berlim em 1859, causados principalmente pela mudança de trono na Prússia e, a partir de 1866, pela vitória prussiana sobre a Áustria e o sucesso na cena $14 \mathcal{1}$ política alemã e internacional de Otto von Bismarck.

\section{Bismarckismo de Droysen?}

O Estado de paz (Friedenstaat) imaginado por Droysen em seus estudos sobre a Altertumswissenschaft, assim como naqueles dedicados à história moderna e à política prussiana, pode ser comparado com as escolhas feitas por Bismarck em relação à política externa, especialmente à luz da convergência de interesses que, a partir de 1866, uniu o grupo liberal e nacional, no qual Droysen pode ser incluído, aos objetivos políticos perseguidos pelo Chanceler (Cf. HINTZE 1990, p. 61-64). Droysen, inicialmente, mostra desconfiança em relação a Bismarck, experimentando uma lenta mudança de opinião, basicamente, após os sucessos prussianos em relação à política externa. A primeira mudança parcial da perspectiva mostrada por Droysen em relação a Bismarck, no Briefwechsel, remonta à primavera de 1864 .

Na carta a Rossmann, de 29 de abril, o historiador pomerano mostra toda a sua satisfação com os êxitos prussianos na Dinamarca (Droysen 1929, p. 837). Neste momento, a crítica a Bismarck dá lugar a uma condescendência parcial relativamente às opções políticas do Chanceler, dado que os primeiros êxitos militares relatados na Dinamarca colocaram a Prússia no centro da política alemã e, mesmo que implicitamente, foi vista uma possibilidade de uma resolução da deutsche Frage naquele sentido kleindeutsch defendido por

\footnotetext{
12 Sobre o prussianismo de Droysen, Cf. Guerra (2013, p. 59-70; 2014; 2016).
} 
Droysen, embora com nuances diferentes ao longo das décadas. Bismarck, pelo menos até a vitória sobre a Áustria, não tem o aplauso de Droysen, que via nele o Junker ultraconservador, fechado ao parlamentarismo e a qualquer reforma em sentido liberal. Ao mesmo tempo, o seu apoio ao Chanceler na política externa, a partir de 1864, parece facilmente verificável: "você sabe - escreve a Sybel em 12 de junho - que eu não estimo muito o Sr. von Bismarck, mas a posição da Prússia na Europa por muito tempo não era tão significativa, tão profundamente entendida e empreendedora como é agora" (DROYSEN 1929, p. 837).

O processo de europeização da questão alemã iniciado e realizado por Bismarck parece concretizar o que o historiador pomerano afirmava a partir de 1849, no ensaio sobre a Prússia e o sistema das grandes potências. Aqui, em vez de uma aproximação de Droysen à política seguida por Bismarck e Guilherme I, poder-se-ia discutir a hipótese oposta. O historiador pomerano, na verdade, via na Prússia o arquiteto da resolução da deutsche Frage, mas a realização prática dessa missão previa para Prússia determinadas opções políticas que apenas a partir de uma certa data o governo de Berlim adotaria. Portanto, com uma hipérbole, poder-se-ia afirmar que não é tanto Droysen que se torna bismarckiano, mas Bismarck que se torna droyseniano. ${ }^{13}$

Em geral, parece que o Friedenstaat associa a perspectiva histórica droyseniana à visão de Bismarck dos acontecimentos políticos da época. Ambos têm como objetivo a formação de um Estado alemão no centro da Europa capaz de funcionar como um termômetro para os interiores e cada vez mais instáveis equilíbrios políticos continentais. Os desafios do quadro político europeu remetem para a desconfiança substancial quanto às relações de força que as Großmächte teriam estabelecido com o Reich. O historiador pomerano, como o Chanceler, sabia que, embora se estabilizasse, a situação geral internacional não coincidiria, à época, com uma paz partilhada por todos. Isso pode explicar, em última instância, que o crescimento do exército e a sábia política externa de Bismarck, bem como uma certa atitude defensiva mostrada por Droysen, traduziria a consciência de que um relaxamento do Reich de um ponto de vista militar e diplomático poderia ser interpretado pelas grandes potências como um sinal de fraqueza do Estado alemão, recém-nascido, despertando nele, ao mesmo tempo, as ambições expansionistas.

No entanto, sobre esse ponto, o Chanceler dava mostras de uma clarividência política ausente nas páginas do professor pomerano. Enquanto ele oscilava entre a superação do sistema das grandes potências, a inclusão da Prússia nesse sistema e a formação por parte do Estado prussiano, à frente na defesa dos Estados menores, de um bloco oposto àquele formado por Großmächte, Bismarck, por sua vez, considerava que as vitórias prussianas em 1866, 1871, e a subsequente formação do Reich representariam o ápice das conquistas alemãs. Ele não tinha ilusões nem de superar o sistema das grandes potências, nem de poder conquistar o espaço político para a formação de uma aliança entre a Prússia e os Estados menores do continente. O resultado,




todavia, parece ser o mesmo: a estabilização do continente por meio do Reich; enquanto o itinerário a ser seguido se mostrava diferente. O historiador Droysen acreditava que o sistema imposto pelas grandes potências tivesse causado as mais graves rupturas para a Europa e que, portanto, apenas sua subversão por parte do Estado alemão, herdeiro da Prússia do Grande Eleitor, de Frederico II, Stein e York von Wartenburg, poderia gradualmente estabelecer e consolidar a paz dentro e fora das suas fronteiras.

Aqui, a mediação da história parece decisiva na formação do ideal político droyseniano, mas, por outro lado, parece expô-lo a críticas às que não é fácil responder. Qualquer escolha por parte do Reich mantendo a aliança entre as grandes potências teria sido interpretada em termos de uma Machtpolitik aplicada para interromper um determinado sistema e substituí-lo por outro completamente diferente que teria previsto uma paz generalizada, mas sempre colocada sob a égide da Alemanha e seus aliados. Embora animado pelas melhores intenções, tal plano político mais parecia ser uma substituição do sistema anterior que uma nova criação. Com as devidas proporções, essa leitura dos acontecimentos políticos europeus pode ser feita junto com a representação da paz macedônia após as vitórias de Filipe e Alexandre, elaborada por Droysen nas duas edições da Geschichte Alexanders des Großen. Nesse trabalho, a Pérsia tinha o mesmo papel desempenhado pelas grandes potências nas obras da história moderna, enquanto o projeto político perseguido por Alexandre, o macedônio, substituía o poder persa pelo macedônio.

146 Embora Droysen, nas obras sobre o helenismo e naquelas dedicadas à história prussiana, particularmente em Geschichte der preussischen Politik, tenha procurado restaurar uma imagem do pluralismo de escolhas em eventos históricos - como na Liga de Corinto ou na dos princípios de Frederico II - , a sua maior preocupação está sempre voltada à relação que na história liga a unidade e o papel das grandes personalidades, a fim de encontrar os elementos últimos capazes, em todos os momentos, de dar estabilidade à organização estatal. Por outro lado, esse tipo de leitura parece ter como corolário um conceito como o de liberdade, enquanto o que cada articulação das relações estatais teria de garantir fica em segundo plano.

Por último, extrair da obra de Droysen uma apreciação global a respeito de Bismarck é muito difícil (Cf. HOLBORN 1973, p. 263; VOCI 2009). ${ }^{14}$ Ferrenho opositor de qualquer projeto político conservador e junkerlich como o que Bismarck, pelo menos até certa data, encarnou, Droysen, embora modificando radicalmente as suas opiniões, expressaria esse movimento por meio de esporádicos testemunhos e sempre em trocas epistolares. Em outras palavras, de um historiador que em sua obra dedicou amplo espaço para a discussão daquelas figuras que movem a história, de Alexandre a Frederico, o Grande, seria de se esperar que, em meio aos retratos dos grandes, para enfatizar a sua grandeza de ação, fosse reservado também um lugar a Bismarck, mas Droysen

${ }^{14}$ Finalmente, para uma discussão recente e importante da historiografia e do pensamento político de Droysen, ver o trabalho de Assis 2014. Sobre este ensaio, ver guerra (2015). 
reconhece no Chanceler méritos limitados. Bismarck, portanto, aos olhos do historiador de Alexandre, nunca vai aparecer como um Geschichtsbeweger stricto sensu, mas sim como um político astuto que, ajudado pelo momento histórico, foi capaz de realizar o que alguns grandes personagens que o precederam na história prussiana não foram capazes de fazer: unificar a Alemanha em torno da Prússia e dar ao Estado prussiano, em primeiro lugar, e ao Reich, em segundo, uma dimensão internacional até então desconhecida.

\section{Referências bibliográficas}

ASSIS, Arthur Alfaix. What is history for? Johann Gustav Droysen and the functions of historiography. New York: Berghahn Books, 2014.

BRAVO, Benedetto. Philologie, histoire, philosophie de I'histoire. Etude sur J.G. Droysen historien de I'antiquité. Wrocklaw-Varsovie-Cracovie: Zaklad Narodowy Imienia Ossolinskich. Wydawnictwo Polskiej Akademii Nauk, 1968.

CERVELLI, Innocenzo. Droysen dopo il 1848 e il "Cesarismo". Quaderni di storia, n. 1, p. 15-56, 1975.

Liberalismo e conservatorismo in Prussia 1850-1858. Bologna: Il Mulino, 1983.

. La Germania dell'ottocento. Un caso di modernizzazione conservatrice. Roma: Editori Riuniti, 1988.

DROYSEN, Johann Gustav. Geschichte der preußischen Politik. Leipzig: Verlag von Veit \& Comp., 1855/1886. 15 voll.

- Der Staat der großen Kurfürsten. In: Geschichte der preußischen Politik. Leipzig: Verlag von Veit \& Comp., 1870a. v. III/I/I.

. Zur Geschichte Friedrichs I und Friedrich Wilhelms I von Preußen. In: Geschichte der preußischen Politik. Leipzig: Verlag von Veit \& Comp., 1870. v. IV/IV/IV.

Der Staat des großen Kurfürsten. In: Geschichte der preußischen Politik. Leipzig: Verlag von Veit \& Comp., 1871a. v. III/II/II.

. Friedrich der Große. In: Geschichte der preußischen Politik. Leipzig: Verlag von Veit \& Comp., 1874. v. V/I. Friedrich der Große. In: . Geschichte der preußischen Politik. Leipzig: Verlag von Veit \& Comp., 1876. v. V/II.

- Friedrich der Große. In: Geschichte der preußischen Politik. Leipzig: Verlag von Veit \& Comp., 1881. v. V/III.

. Friedrich der Große. In: Geschichte der preußischen Politik. Leipzig: Verlag von Veit \& Comp., 1886. v. V/IV.

Vorlesungen über die Freiheitskriege. 2 Bde. Kiel: UniversitätsBuchhandlung, 1846. 
Briefwechsel. 2 Bde, hrsg. v. HÜBNER, Rudolf, Stuttgart. Berlin, Leipzig: Deutsche Geschichtsquellen des 19. Jahrhunderts 25 u. 26, 1929. . Istorica. In: CAIANIELLO, Silvia (Org.). Istorica. Napoli: Guida, 1994. . Die attische Communalverfassung. In: Kleine Schriften zur alten Geschichte. 2 Bde., hrsg. v. HÜBNER, Ernst. Leipzig: Verlag von Veit \& Comp., 1893/1894, p. 328-385.

Die Preußen und das System der Großmächte. In: DROYSEN, J. G. Politische Schriften. hrsg. v. GILBERT, Felix. München-Berlin: Verlag von R. Oldenbourg, 1933, p. 212-229.

Zur Charakteristik der europäischen Krisis. In: DROYSEN, J. G. Politische Schriften. hrsg. v. GILBERT, Felix. München-Berlin: Verlag von R. Oldenbourg, 1933, p. 302-342.

- Die politische Stellung Preußens. In: DROYSEN, J. G. Politische Schriften. hrsg.v. GILBERT, Felix. München-Berlin: Verlag von R. Oldenbourg, 1933, p. 30-64.

England und Preußen 1740-1746. Zeitschrift für preußische Geschichte und Landeskunde, n. 16, p. 502-534, 1879.

FLEISCHER, Dirk. Geschichtserkenntnis als Gotteserkenntnis. Das theologische Fundament der Geschichtstheorie Johann Gustav Droysens. In: BLANKE, Horst Walther (Org.). Historie und Historik. 200 Jahre Johann Gustav 148 Droysen. Festschrift für Jörn Rüsen zum 70. Geburtstag. Köln-WeimarWien: Böhlau 2009, p. 73-89.

FLENLEY, Ralph; SPENCER, Robert. Storia della Germania. Dalla Riforma ai nostri giorni. Milano: Garzanti, 1965.

GILBERT, Felix, Johann Gustav Droysen und die preussisch-deutsche Frage. München-Berlin: Verlag von R. Oldenbourg, 1931.

GUERRA, Francesco. Questa fu la Prussia. Il carteggio tra Johann Gustav Droysen e Heinrich von Treitschke. In: Annali dell'Istituto Italiano per gli Studi Storici, v. XXIII, p. 568-633, 2008.

. Resenha de: ASSIS, Arthur Alfaix: What Is History For? Johann Gustav Droysen and the Functions of Historiography. Berlin: H-Soz-Kult, 2015.

. Riflessioni sul prussianesimo di Johann Gustav Droysen. Ricerche di Storia politica, n. 1, p. 59-70, 2013.

Il (Super)Reich prussiano e luterano di Droysen tra Macht e Friedenspolitik. Roma: Aracne, 2014.

. 'Conjunge et imperabis'. Einheit e Freiheit nel pensiero politico di Johann Gustav Droysen, Napoli: Società Editrice Il Mulino, 2016.

HALTERN, Utz. Geschichte und Bürgertum. Droysen - Sybel - Treitschke. Historische Zeitschrift, n. 259, p. 59-107, 1994. 
HARDTWIG, Wolfgang. Von Preußens Aufgabe in Deutschland zu Deutschlands Aufgabe in der Welt. Liberalismus und Borussianisches Geschichtsbild Zwischen Revolution und Imperialismus. Historische Zeitschrift, v. 231, p. 277-280, 1980.

HEGEL, Georg Wilhelm Friedrich. Lezioni sulla filosofia della storia. In: BONACINA, Giovanni; SichIRollo, Livio (Org.). Lezioni sulla filosofia della storia. Roma-Bari: Laterza, 2003.

HINTZE, Otto. Storia, sociologia, istituzioni. In: Di Costanzo, Giuseppe (Org.). Storia, sociologia, istituzioni. Napoli: Morano, 1990.

HOCK, Wilhelm. Liberales Denken im Zeitalter der Paulskirche. Münster: Aschendorffsche Verlagsbuchhandlung, 1957.

HOLBORN, Hajo. Storia della Germania moderna (1840-1945). In: MAGLIANO, Lydia (Org.). Storia della Germania moderna (1840-1945). Milano: Rizzoli, 1973.

JORDAN, Karl. Von Dahlmann zu Treitschke. Die Kieler Historiker im Zeitalter der schleswig-holsteinischen Bewegung. Archiv für Kulturgeschichte, n. 49 , p. 262-296, 1967.

LUTZ, Heinrich. Tra Asburgo e Prussia. Bologna: Il Mulino, 1992.

MANN, Bernhard. Das Ende der Deutschen Nationalversammlung im Jahre 1849. Historische Zeitschrift, n. 214, p. 265-309, 1972.

MCGLEW, James F. J.G. Droysen and the Aeschylean Hero. Classical Philology, n. 79, p. 1-14, 1984.

MEINECKE, Friedrich. Drei Generationen deutscher Gelehrtenpolitik. Historische Zeitschrift, n. 125, p. 248-283, 1922.

NIPPEL, Wilfried. Johann Gustav Droysen. Ein Leben zwischen Wissenschaft und Politik. München: C.H. Beck, 2008, p. 48.

PAETROW, Stephan. Johann Gustav Droysen in Jena. Saarbrücken: VDM Verlag Dr. Müller, 2008.

SCHULZE, Hagen. DerWeg zum Nationalstaat. Die deutsche Nationalbewegung vom 18. Jahrhundert bis zur Reichgründung. München: DTV, 1985.

TAYLOR, Alan John Percivale. Storia della Germania. Bari: Laterza, 1963.

TREITSCHKE VON, Heinrich. La Costituzione dello Stato. In: RUTA, Enrico (Org.). La politica. Bari: Laterza, 1918. v. III.

VOCI, Anna Maria. Il Reich di Bismarck. Storia e storiografia. Roma: Edizioni di storia e letteratura, 2009.

WELSKOPP, Thomas. Der "echte Historiker" als "richtiger Kerl". Neue Veröffentlichungen (nicht nur) zum 200. Geburtstag von Johann Gustav Droysen. Historische Zeitschrift, n. 288, p. 385-407, 2009. 